\title{
Calibration and Quantitative Forecast of Extreme Daily Precipitation Using the Extreme Forecast Index (EFI)
}

\author{
Quan Dong \\ National Meteorological Center, Chinese Meteorological Administration, Beijing, China \\ Email: dongquan@cma.gov.cn
}

How to cite this paper: Dong, Q. (2018) Calibration and Quantitative Forecast of Extreme Daily Precipitation Using the Extreme Forecast Index (EFI). Journal of Geoscience and Environment Protection, 6, 143-164.

https://doi.org/10.4236/gep.2018.62010

Received: January 19, 2018

Accepted: February 25, 2018

Published: February 28, 2018

Copyright $\odot 2018$ by author and Scientific Research Publishing Inc. This work is licensed under the Creative Commons Attribution International License (CC BY 4.0).

http://creativecommons.org/licenses/by/4.0/

\begin{abstract}
Based on the extreme forecast index (EFI) of ECMWF, the "observed" EFI (OEFI) of observation is defined and the EFI is calibrated. Then the EFI equivalent percentile (EFIEP) and EFI equivalent quantile (EFIEQ) are designed to forecast the daily extreme precipitation quantitatively. The formulation indicates that the EFIEP is correlated not only to the EFI but also to the proportion of no precipitation. This characteristic is prominent as two areas with nearly same EFIs but different proportions of no precipitation. Cases study shows that the EFIEP can forecast reliable percentile of daily precipitation and $100 \%$ percentiles are forecasted for over max extreme events. The EFIEQ is a considerable tool for quantitative precipitation forecast (QPF). Compared to the probabilistic forecast of ensemble prediction system (EPS), it is quantitative and synthesizes the advantage of extreme precipitation location forecast of EPS. Using the observations of 2311 stations of China in 2016 to verify the EFIEP and EFIEQ, the results show that the forecast biases are around 1 . The threat scores (TS) for 20 years return period events are about 0.21 and 0.07 for 36 and 180 hours lead times respectively. The equivalent threat scores (ETS) are all larger than 0 and nearly equal to the TS. The TS for heavy rainfall are 0.23 and 0.07 for 36 and 180 lead times respectively. The scores are better than those of high resolution deterministic model (HRDet) and show significant forecast skills for quantitative forecast of extreme daily precipitation.
\end{abstract}

\section{Keywords}

Extreme Forecast Index (EFI), Extreme Precipitation, Quantitative Precipitation Forecast (QPF) 


\section{Introduction}

Extreme precipitations always accompany disasters in China [1]. To forecast them is the primary goal globally. Recently, as the development of ensemble prediction system (EPS), many tools have been developed to forecast them and the forecast skills arise steadily [2].

One of the very popular tools is the Extreme Forecast Index (EFI) [3] of European Centre of Medium Weather Forecast (ECMWF) which is the weighted integral of the differences between the cumulative probability distribution functions (CPDF) of ECMWF EPS and the "model" climate established from the re-forecast dataset. The EFI is based on the hypothesis that if the forecast "weather" is extreme and relative to the "model" climate, the real weather would be an extreme event compared to the real climate [4]. Because the EFI uses the same model re-forecast dataset, it is free of model bias. And it is a good tool for the area where observations are scarce. Many researches show that the EFI is an effective indication for extreme events, including extreme wind [5], windstorms [6] and heavy rainfall [7].

However, the disadvantage of EFI is obvious too, because its meaning is implicit [8]. Typical question is: what does precipitation EFI of 0.7 mean. Is it the probability or intensity of some special event $-50 \mathrm{~mm} /$ day precipitation for example? Forecasters cannot directly use it to forecast the probability or intensity of the extreme precipitation events.

To address these criticisms, many researches have been done. There are mainly two kinds of them. One is EFI thresholds estimation through verification for the need of application. Boisserie et al. [6] used the EFI and "Shift of Tails" (SOT) of 30 years to calibrate the forecast for extreme windstorms in France and got the thresholds and measures for different ranks events through verification. Petroliagis and Pinson [5] verified the gust EFI for three airports' daily wind extremes and the EFI thresholds are estimated. Dong et al. [9] verified the EFI and SOT for extremely high and low temperature and extreme precipitation in China and estimated the thresholds for different percentiles.

The other kind of research is producing new products whose meanings are explicit for extreme weather forecast. Prates and Buizza [8] introduced a product of probability of return level (PRET) from the observation and re-forecast datasets. Using the Generalized Extreme Value (GEV) distribution, the return levels for different return periods of observation and model are estimated and the PRET is calculated for different return levels. It not only can provide similar information to the EFI but also is more explicitly understood. Standardized Anomaly Forecasting (SAF) is another product for extreme weather forecast which is the normalized difference between the forecast and expected value of climate distribution [10]. SAF is normalized by the climatological standard deviation, so it can be immediately understood. Guan and Zhu [11] verified and compared the SAF and EFI, and found that the SAF and EFI are highly correlated and the 
performances of them for extreme cold events in America are nearly similar.

The EFI has its own advantage. By using the same model re-forecast as "model" climate, the EFI is considered independent of model bias which is common for numeric weather prediction models and difficult to be estimated and corrected [12] [13] [14]. On the other hand, through revised formulation of EFI and continuous improvement of re-forecast suite [4], the forecast skill of EFI for extreme events has been improving continuously.

The EFI is the integral of the differences between the CPDFs of EPS and "model" climate. It concentrates the information. Meanwhile there is no observation index corresponding to the EFI explicitly. It made the EFI difficult to be understood directly. To make the meaning of EFI significantly, the observation index-the "observed" EFI (OEFI) is established firstly from the daily precipitation amount observation and real climate of meteorological stations in this work. Then, the OEFI and EFI are compared with each other and their mapping relationship is estimated to calibrate the EFI. The EFI equivalent percentile (EFIEP) and equivalent quantile (EFIEQ) are designed based on the calibrated EFI. The EFIEP is the percentile forecast and the EFIEQ is a quantitative forecast of extreme event. The daily precipitation amount observation in 2016 of China is used to verify the EFIEP and EFIEQ.

This paper studies the two forecast modes of OEFI and EFI in order to improve the capability of calibration and quantitative forecast of extreme daily precipitation.

After this introduction, the formulations of EFI, calibration approach, EFIEP, EFIEQ and the datasets used are described in Section 2. In Section 3, two extreme rainfall cases and one extreme snowfall case of China are presented and the verification results are shown in Section 4. The conclusions and discussions are drawn in Section 5.

\section{Methods and Datasets}

\subsection{EFI and Definition of "Observed" EFI (OEFI)}

To measure the differences between the CPDFs of EPS and "model" climate, the EFI is a weighted integral of the differences. The weights make the EFI more sensitive to the tails of probability density function [15]. For the precipitation, of which there are many samples of no precipitation, the EFI formulation is:

$$
\mathrm{EFI}=\frac{1}{A\left(\theta_{0}\right)} \int_{p_{0}}^{1} \frac{p-F_{f}(p)}{\sqrt{p(1-p)}} \mathrm{d} p,
$$

where $p$ is the "model" climate probability and $F_{f}(p)$ is the EPS probability of the exact quantile of climate probability $p$ (Figure 1 ). $p_{0}$ is the proportion of no precipitation days in the climate and $\theta_{0}=\arcsin \sqrt{p_{0}}$ and $A\left(\theta_{0}\right)=\frac{1}{2} \sin 2 \theta_{0}-\theta_{0}+\frac{\pi}{2}$. The $A\left(\theta_{0}\right)$ makes the value of EFI in the interval of $[-1,1]$ and it's a function of $p_{0}$. Because of the weighting of $\frac{1}{\sqrt{p(1-p)}}$, the EFI 


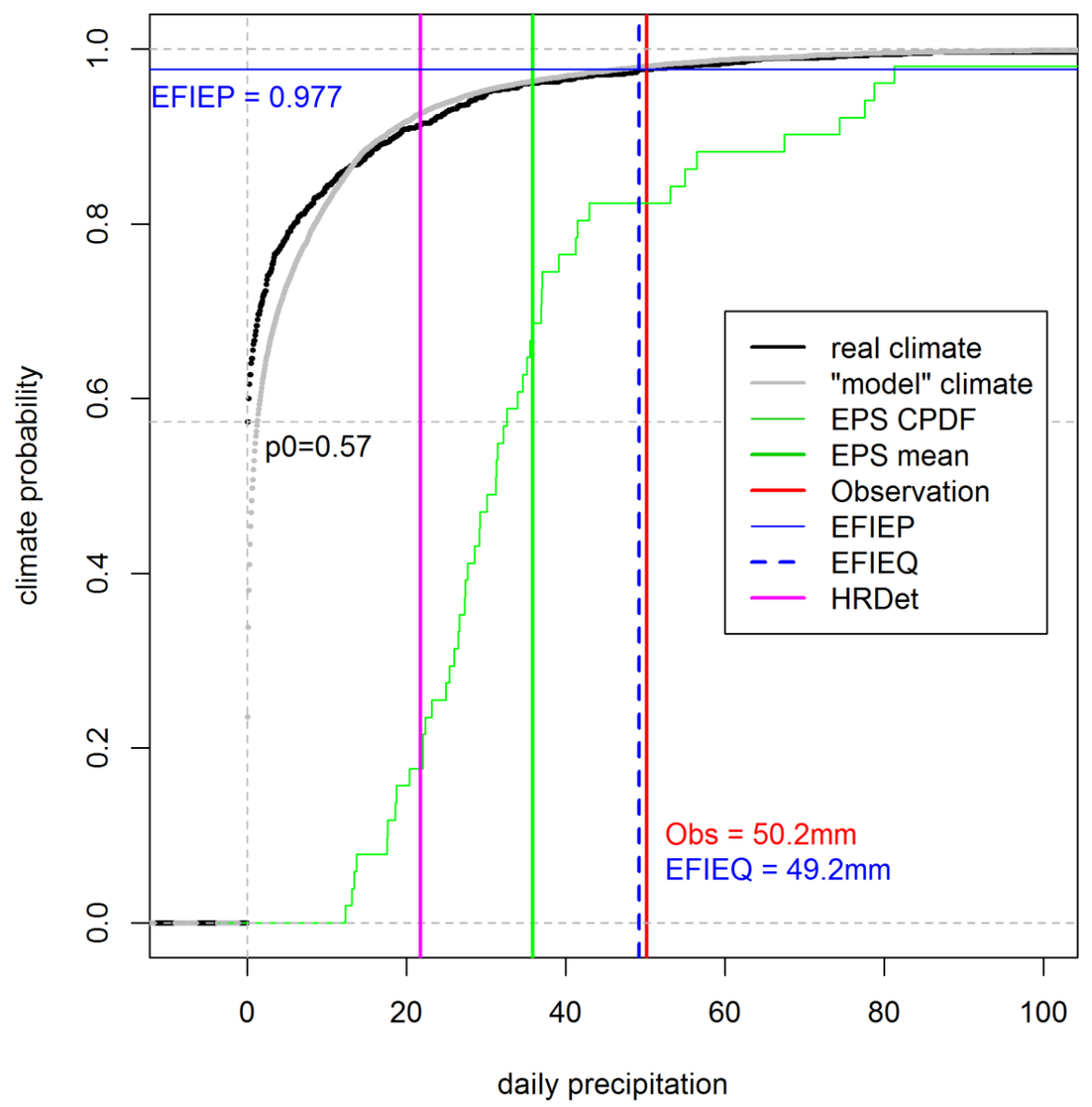

Figure 1. Real climate, observation and EPS 48-h forecasts of 24 hours precipitation amount from 00 UTC 19 to 00 UTC 20 July 2016 of Beijing with corresponding EFI of 0.651. The forecast of ECMWF high resolution deterministic model (HRDet) is also shown. The EFIEP is 0.977 and EFIEQ is $50.2 \mathrm{~mm}$ that is better than the EPS mean and HRDet. Because of lack of re-forecast dataset, the "model" climate is shown schematically.

is sensitive to the tails of probability distribution [15].

The EFI cannot be understood directly and there is no "observations" related to the EFI directly. Then, define the "observed" EFI (OEFI) to be the integral of differences between CPDFs of real climate and real weather. The cumulative probability of real weather takes the value 1 or 0 according to whether the climatic quantile is larger than the observation or not, same to the approach of Brier score for probability forecast verification [16]. If the percentile of observation corresponding to the real climate is $p_{1}$, the OEFI can be written as:

$$
\mathrm{OEFI}=\frac{1}{A\left(\theta_{0}\right)}\left(\int_{p_{0}}^{p_{1}} \frac{p}{\sqrt{p(1-p)}} \mathrm{d} p+\int_{p_{1}}^{1} \frac{p-1}{\sqrt{p(1-p)}} \mathrm{d} p\right)
$$

Integrating this equation can get the result:

$$
\mathrm{OEFI}=1-\frac{\pi-2 \theta_{1}}{A\left(\theta_{0}\right)}
$$


in which $\theta_{1}=\arcsin \sqrt{p_{1}}$. The OEFI is a function of $p_{1}$ and $p_{0}$ and is an increasing function of $p_{1}$ and decreasing one of $p_{0}$ (Figure 2). It is obvious that the percentile of precipitation relative to the climate must be larger than the proportion of no precipitation (Figure 2). The OEFI is equal to -1 , only when the $p_{0}$ is 0 and $p_{1}$ is 0 too (Figure 2). Because $\theta_{1}$ is between the interval of $[0, \pi / 2]$ and $A(\theta)$ is a decreasing function of $\theta$ between the range of $[\pi / 2,0]$, OEFI is between the interval of $[-1,1]$ which is same as the EFI. When the precipitation is equal to or larger than the max of the real climate, the $p_{1}$ is equal to 1 and the OEFI is equal to 1 consistently. If the observation is the median relative to the climate $-p_{1}$ is 0.5 , and $p_{0}$ is 0 , OEFI is 0 . It means that OEFI is negative if the observation is below the climate median, and positive if the observation is above the climate median. This characteristic is similar to the EFI [3]. When the $p_{1}$ is equal to $p_{0}$ the OEFI is not constant and different from $p_{0}$. For extreme events of $95 \%$ percentile relative to the climate, the OEFIs are about 0.71 for $p_{0}$ equal to 0.1 . When the $p_{0}$ is equal to 0.6 , which is a typical value for Yangtze and Huaihe River basins of China in summer, the OEFI is about 0.62 , which is close to the suggested thresholds by ECMWF.

\subsection{Relationship between the EFI and OEFI}

Figure 3 shows the scatter plot between the 36-h EFI forecast and the corresponding OEFI for the 2311 meteorological stations of China in 2015. The EFI is

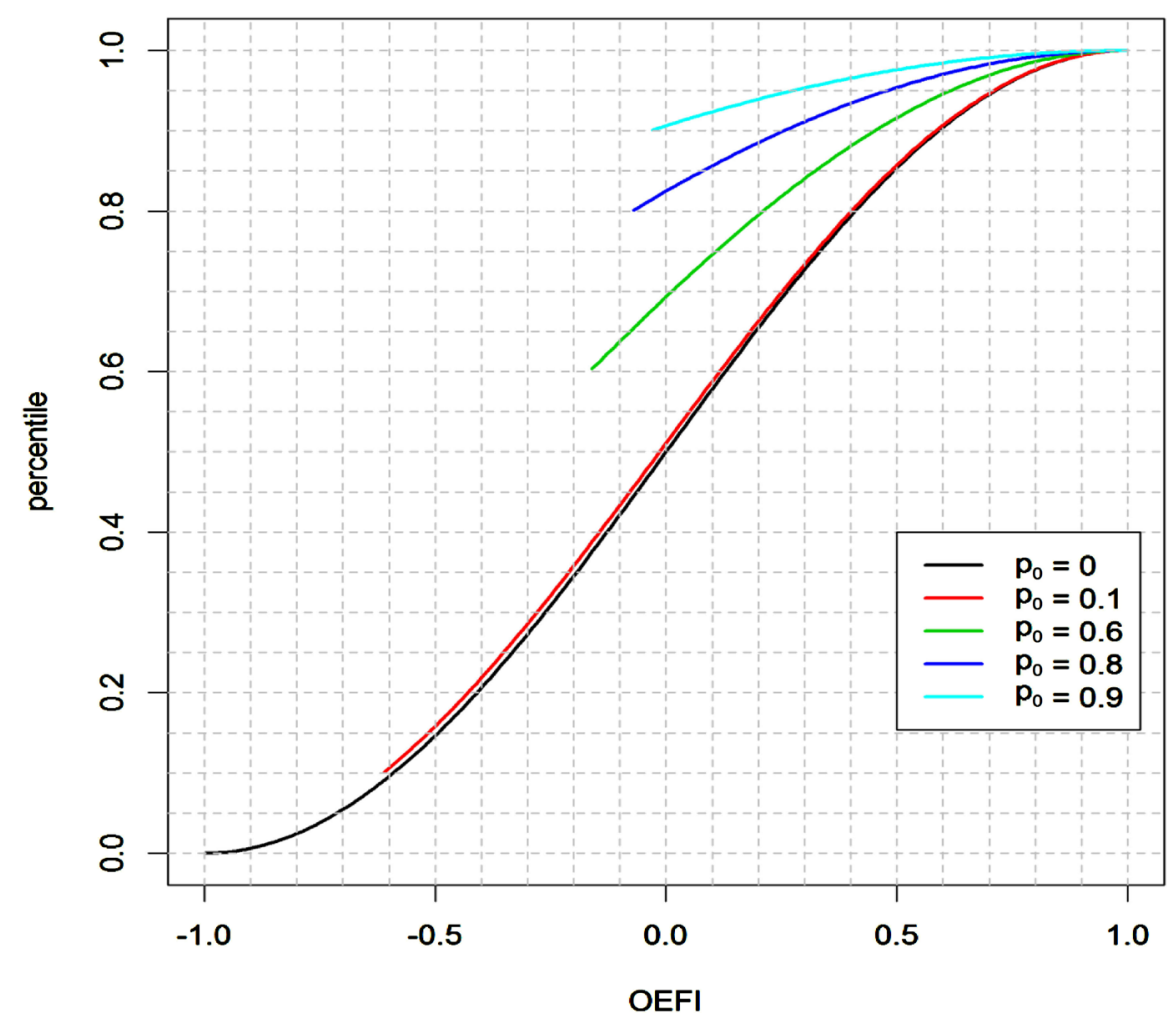

Figure 2. The "observed" EFI (OEFI) as a function of daily precipitation percentile $\left(p_{1}\right)$ and the proportion of no precipitation $\left(p_{0}\right)$. 


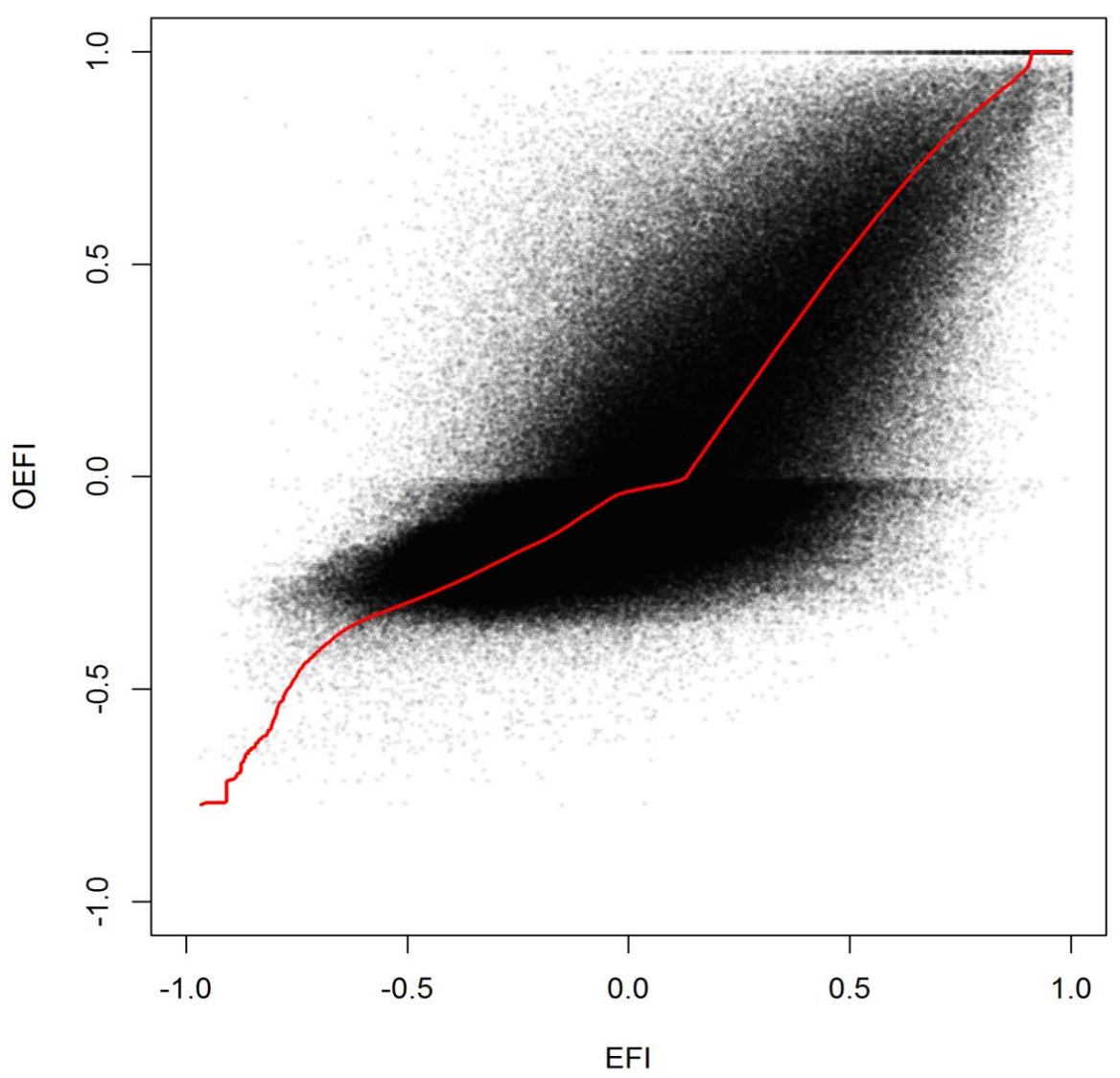

Figure 3. Relationship between EFI and "observed" EFI (OEFI) using the observations of 2311 stations of China in 2015 and the corresponding EFI forecast of 36 hours lead time. The red line indicates the quantile mapping relationship between EFI and OEFI.

correlated to the OEFI significantly. As the EFI tends to 1, the OEFI leans towards 1 too. It means that when the forecast "weather" is an extreme event relative to the "model" climate the real weather is likely to be an extreme event according to the real climate. The hypothesis of EFI is acceptable.

The scatter points are located at the diagonal mostly (Figure 3) which means the OEFI value is nearly same to the EFI qualitatively and the definition of OEFI is reasonably. In west of China and north of China, there is always no precipitation for a month $-p_{0}$ is 0 and $p_{1}$ is 0 too, so the OEFIs are 0 frequently. On the other hand, the EPS would forecast precipitation probability at these areas always, and the EFI would not be 0 . Therefore, there are more 0 of OEFI compared to the EFI (Figure 3).

Because the precipitation, precipitation EFI and OEFI are not normally distributed, the standard linear regression with least squares methods cannot be used to estimate the relationship [17]. So, the quantile mapping method is used to map the EFI to the OEFI [18] [19]. The method is simple: since the samples of OEFI are the same to that of EFI, the EFI quantiles are directly mapped onto the OEFI quantiles, in which the quantiles are replaced by the ranks. The red line in Figure 3 indicates the quantile-quantile (Q-Q) plots of the 36-h EFI forecast 
against the corresponding OEFI for the 2311 stations of China in 2015. The quantile mapping method is applied to the EFI to calibrate it and would make the expectation of forecast bias to be 1 .

With the calibrated EFI (CEFI), the expected percentile of precipitation event-defined as EFI equivalent percentile (EFIEP), could be calculated with the inverse function of (3):

$$
\mathrm{EFIEP}=\sin ^{2}\left(\theta_{1}\right)=\sin ^{2}\left[\frac{\pi}{2}-\frac{A\left(\theta_{0}\right)}{2}(1-\mathrm{CEFI})\right]
$$

Figure 4 shows the 36-h forecasts of EFI against the observed percentile of the 2311 stations of China in 2016 with $p_{0}$ of samples between 0.59 and 0.61 and the theoretical relationship between the EFI and the EFIEP from Equation (4) with $p_{0}$ equal to 0.6 for different lead times. This scatterplot is common and wide used in the EFI verification and application and the distribution pattern is similar to the past works [5] [6] [9]. It shows significant correlation between the EFI and the percentiles of events and can be used to verify the EFI and determine the thresholds for exact percentile events. Compared to linear regression, the non-linear correlation of Equation (4), using calibrated EFI with quantile mapping, is more reasonable.

The black line in Figure 4 indicates the relationship of Equation (4) with no EFI calibration. It is close to the observations, which indicates that the hypothesis of EFI is reasonably. For the same EFIEP, the EFI thresholds decrease with increasing forecast times, which is consistent with the observational verifications [20]. This characteristics cannot be shown by the no EFI calibration. As the EFI

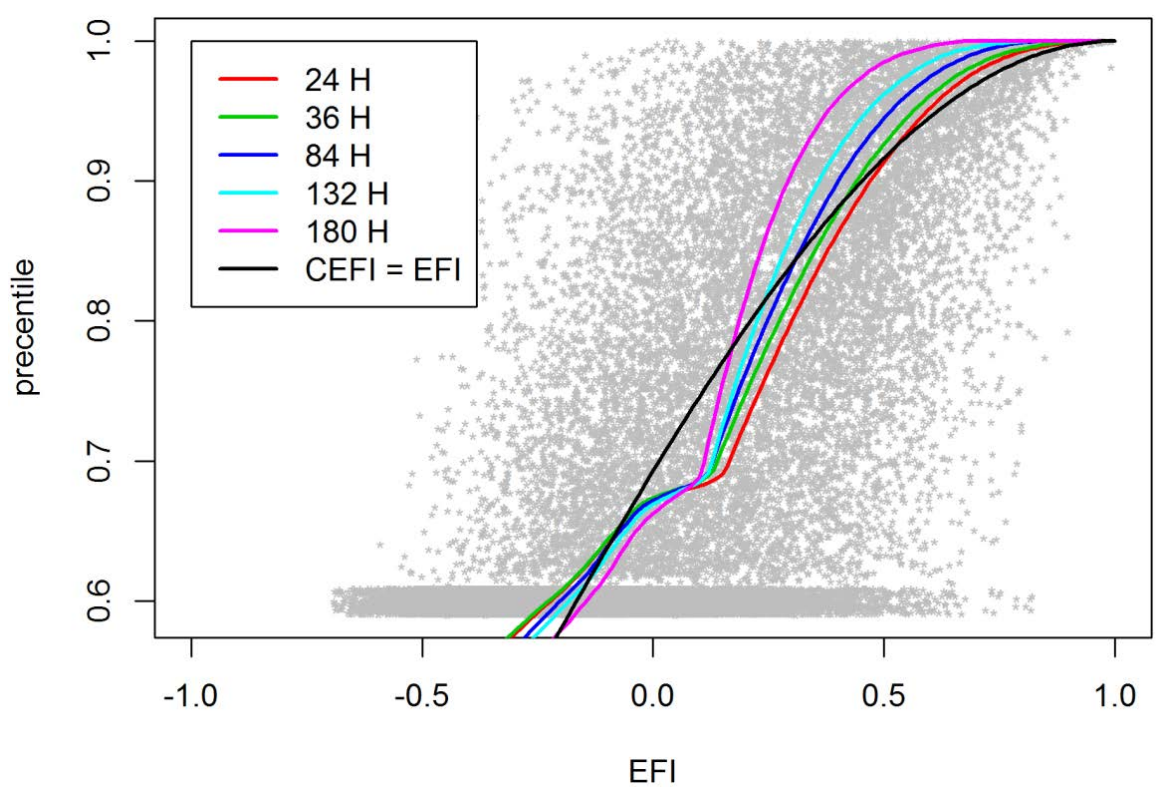

Figure 4. Scatterplot between the EFI of 36 hours lead time and the corresponding observation percentiles for the 2311 stations of China in 2016 with samples $p_{0}$ between 0.59 and 0.61 and the theoretical relationship between the EFI of different lead times and the observation percentiles with $p_{0}$ equal to 0.6 (solid lines). 
tends to 1 , the observed and theoretical EFIEP tend to 1 too which would no be expected for linear regression relationship.

From this formulation of Equation (4), it is indicated that the EFIEP is an increasing function of no precipitation proportion $p_{0}$ and EFI, because $A(\theta)$ is a decreasing function and CEFI is an increasing function of EFI. When the EFI is 1 which means that all the members exceed the "model" climate maximization, the EFIEP is 1 too. It means that the quantitative forecast of extreme precipitation is equal to or exceeds the real climate maximization.

Making the $p_{0}$ equal to 0.6 , which is a characteristic value at the Yangtze River basin of China in summer, the EFI is 0.73 and 0.83 for $97.5 \%$ and $99 \%$ EFIEP respectively. These values are close to the optimal EFI threshold for forecasts of 97.5\% and $99 \%$ percentile precipitation events under the criteria of TS maximization [9]. So, the EFIEP is an effective index for quantitative forecast of extreme precipitation and its meaning is understandable directly. With the EFIEP and real climate, the EFI equivalent quantile (EFIEQ) is defined and estimated as a quantitative forecast of extreme daily precipitation.

\subsection{Real Climate and Verification Dataset}

The primary factor of the EFIEP is the establishment of real climate. In the formulation of EFI, the "model" climate is based on 5 weeks of re-forecasts run every Monday and Thursday with 10 perturbed and 1 unperturbed member of the last 20 years. There are totaling $11^{\star} 9^{\star} 20=1980$ re-forecast samples of the "model" climate for each grid point. This approach allows seasonal variations and model drift to be taken into account [4]. The "model" climate is within a sampling moving window about 29 days and represents the last 20 years variation.

The real climate should maintain these features of "model" climate. The sampling moving window of 31 days is applied. The sample number of real climate should be close to that of "model" climate. The sampling years should be as long as possible to collect enough samples. But, it could not be too long to avoid new interdecadal variations. The precipitation observations have been recorded from 1951 for about 600 stations. Until 1980s, the stations increase to about 2300 . However, the climate and precipitation exhibit decadal variability [21]. East Asian climate has experienced an interdecadal scale transition since the late 1970s [22] [23] [24], including precipitation [25]. The extreme precipitation exhibits changes in the past 60 years in China [1]. This shifting signal in late 1970s does not exist in the "model" climate, because only the last 20 years re-forecast dataset is used. The real climate should exclude this signal too. Therefore, the observations from 1981 to the last year are used to establish the real climate.

For the calculation of the OEFI of 2015 in Figure 3 and Figure 4, the 31 days of observations centered at the calendar day from 1980 to 2014 are used as the real climate. For each station and calendar day of a year, the real climate is different. There are $31^{\star} 35=1085$ samples of real climate compared to the 1980 of 
"model" climate. For the forecast verification in 2016, the time period of real climate is from 1981 to 2015 to preserve the sample number, which is same as the "model" climate.

In this work, the daily precipitation dataset from National Meteorological Information Center of Chinese Meteorological Administration is used [1]. The time period is from 1951 to 2016 and there are 2479 stations over China in this dataset. The stations with less than $365^{\star} 20=7300$ no missing observations are excluded. At last, there are 2311 stations researched in this work.

The OEFIs in 2015 are used to establish the calibration relationship between the EFI and CEFI. Then the approach is applied to the EFI forecast in 2016 and the verification is estimated against the observations.

The return period is used instead of the event percentile related to the real climate. Because 31 days of moving window is applied, the return period is calculated by the formulation:

$$
R P=\frac{1}{31\left(1-p_{1}\right)} .
$$

The unit of $R P$ is year. When the climate max is exceeded and the $p_{1}$ is equal to 1 , the $R P$ is defaulted to 36 years, because the real climate is sampled from 35 years dataset.

\section{Cases Study}

\subsection{Extreme Precipitation in North China}

On 19 and 20 July 2016, extreme precipitation happened at North China around Beijing (Figure 1) and some stations exceeded the maximization of historical records and some exceeded the maximization of July in history [26] [27] [28]. The event was connected to a synoptic scale cyclone. A westerly trough moved from central Asia. As it reached west of North China, south wind advected warm and wet air from South China to ahead of the trough and intensified it significantly. A low pressure system developed rapidly. As the cyclone moved to North China, deepening cyclone and action with the subtropical high of Northwest Pacific (SHNP) at Southeast of the cyclone, a southerly low level jet (SLLJ) was established. This SLLJ characterized by over $20 \mathrm{~m} / \mathrm{s}$ speed at the core and expanded from South China Sea to North China (Figure 5(a)). It advected wet and warm air to North China and formed a vapor belt with specific humidity around $20 \mathrm{~g} / \mathrm{kg}$ expanded from South China Sea to North China. The warm and wet air fueled the cyclone and resulted to the extreme precipitation. At the high level of troposphere, there was a trough at North China and the accompanied high level jet (HLL) was featured (Figure 5(b)). The PV anomaly injection at high level and the secondary vertical circulation accompanied with the HLL, triggered or intensified the convection and precipitation.

The 24 hours precipitation amount from 0000 UTC 19 to 0000 UTC 20 July 2016 is more than $200 \mathrm{~mm}$ at southwest of Hebei province and northeast of Henan 

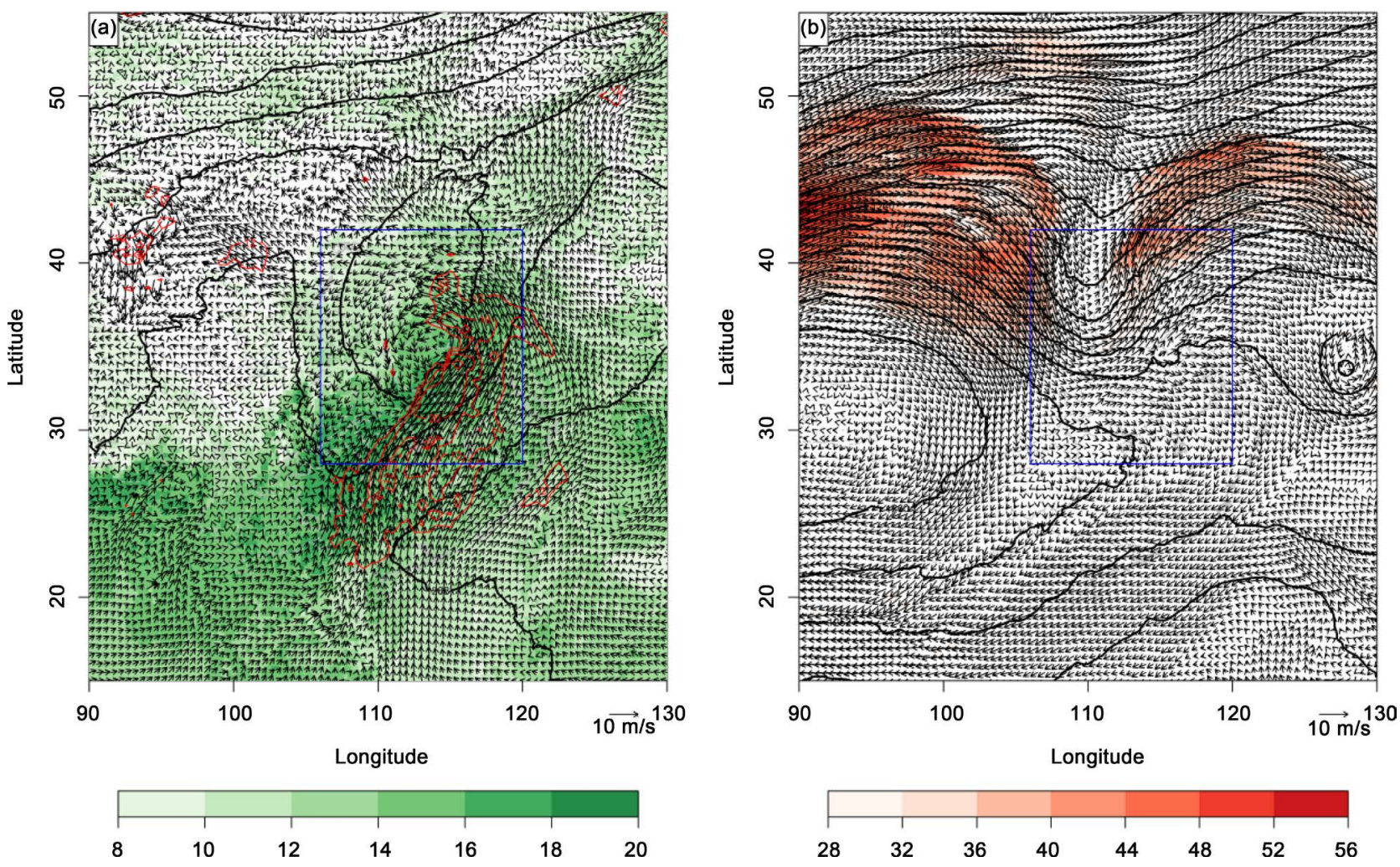

Figure 5. (a) The $500 \mathrm{hPa}$ height (black line every $40 \mathrm{~m}$ ), $850 \mathrm{hPa}$ wind, special humidity (shaded; unit: $\mathrm{g} / \mathrm{kg}$ ) and wind speed (red line every $4 \mathrm{~m} / \mathrm{s}$ from $12 \mathrm{~m} / \mathrm{s}$ ) and (b) $200 \mathrm{hPa}$ height (black line every $40 \mathrm{~m}$ ), wind and wind speed (shaded; unit: $\mathrm{m} / \mathrm{s}$ ) at 1200 UTC 19 July 2016. The blue rectangular indicates the area of Figure 6.

province and some stations precipitation is over $250 \mathrm{~mm}$ (Figure 6(a)). Relative to the real climate, the return periods of daily precipitation at southwest of Hebei, middle of Shanxi, and northeast of Henan provinces are over 35 years which means the maxes of climate were exceeded. The return periods at North China are over 10 years commonly and that of Beijing are about 8 years (Figure 6(b)). The cyclone effected north of North China including Beijing at 20 July 2016 and more precipitation happened in Beijing [26]. Here, just the precipitation happened at 19 July is researched.

The EFI forecast from 16 July onward, which corresponds to lead time of 3 - 4 days, captured the extreme precipitation event well [28]. As Figure 6(c) shows, the 36-h EFI forecast is larger than 0.7 at North China. It reaches 0.9 at middle of Shanxi and southwest of Hebei provinces, which means high probability of extreme precipitation at this area. But how much probability and what is the intensity of the extreme precipitation will happen cannot be told by EFI or SOT. Other information, probability forecast from ensemble prediction system for example, should be considered to answer these questions [4].

With the definition of OEFI and calibration of the EFI, the EFI forecast was converted to EFIEP and EFIEQ. For the 36-h forecast, the EFIEQ are larger than $100 \mathrm{~mm}$ at southwest Hebei and northeast Henan provinces with return periods of about 30 years. The EFIEQ and EFIEP are smaller than the observations. But, 

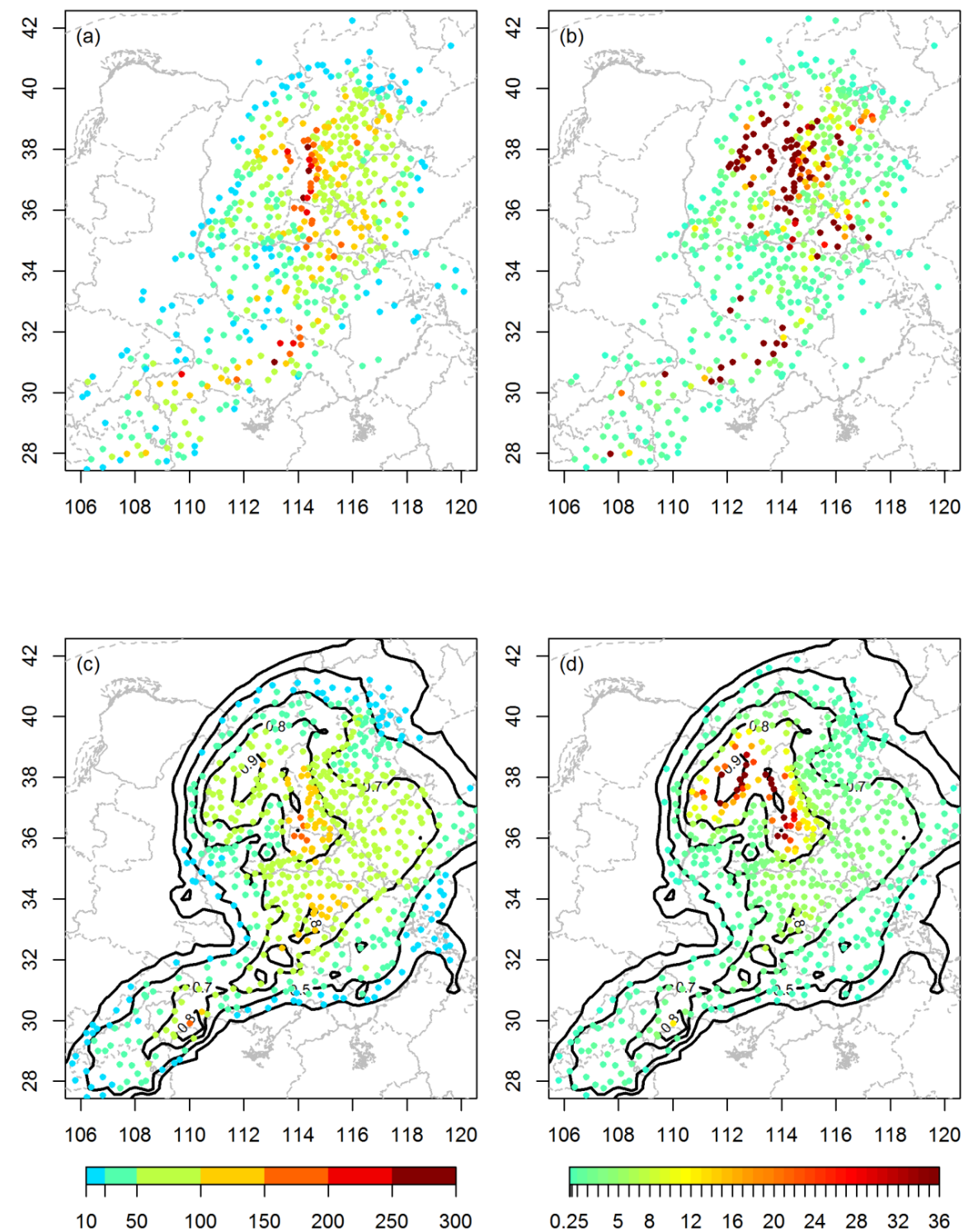

Figure 6. The observation of 24 hours precipitation amount from 0000 UTC 19 to 0000 UTC 20 July 2016 (a) and the return periods relative to the real climate (b) and the corresponding 36-h forecast of EFI (contours), EFIEQ (c), and the return periods (d).

the return period of EFIEP shows some stations exceed the max of climate with 36 years of return period at middle of Shanxi, southwest of Hebei, and northeast of Henan provinces (Figure 6(c), Figure 6(d)). It is consistent with the observations.

The high resolution deterministic (HRDet) forecast always underestimates the precipitation. The 48-h quantitative precipitation forecast (QPF) of HRDet at Beijing is about $22 \mathrm{~mm}$. However the EFIEQ is $49.5 \mathrm{~mm}$ which is closer to the observation of $50.2 \mathrm{~mm}$ (Figure 1). The EFI cannot be understood directly and cannot be solely used to forecast the intensity or probability of extreme precipitation. For extreme events, the HRDet always underestimate the intensity or rar- 
ity. The EFIEQ is a reasonable tool to forecast the extreme precipitation quantitatively.

For 84-h forecast, the EFIEP forecast the percentiles of $100 \%$ at southwest of Hebei and northeast of Henan provinces and the EFIEQ reaching the max of climate (Figure 7). So the EFIEQ cannot forecast the quantitative precipitation over the max of climate. It is the limitation of EFI and the reason of design of SOT. The extreme precipitation at middle of Shanxi province is missed by the EFIEQ and EFIEP which is resulted from the missing forecast of EFI.

The EFI of $84-\mathrm{h}$ forecast is smaller than that of $36-\mathrm{h}$, but the EFIEP and EFIEQ are not smaller than that of 36-h. It indicated the advantage of lead time dependent calibration approach of EFI.

There are some stations' daily precipitation exceeds the max of real climate [26]. These characteristics are indicated by the EFIEP forecast of $100 \%$ percentile. However the amount of daily precipitation was underestimated by the EFIEQ (Figure 7). This is the drawback of quantile estimation from real climate. The EFIEQ cannot exceed the max of real climate from the statistical estimation.

In summary, Figure 6 and Figure 7 is not the same as the main reason is the forecast time is not the same.

\subsection{Typhoon Meranti Heavy Rainfall in East China}

During 14 to 16 September 2016, the "1614" typhoon Meranti affected the mainland of China. Meranti landed at Xiamen, Fujian province at about 1900 UTC 14 September, moved westward to west of Fujian province, and then turned northeast toward East Sea of China through southeast of Anhui province and south of Jiangsu province. The precipitation amounts from 0000 UTC15 to 0000 UTC 16 after landfall are over $50 \mathrm{~mm}$ in most of East China. The max
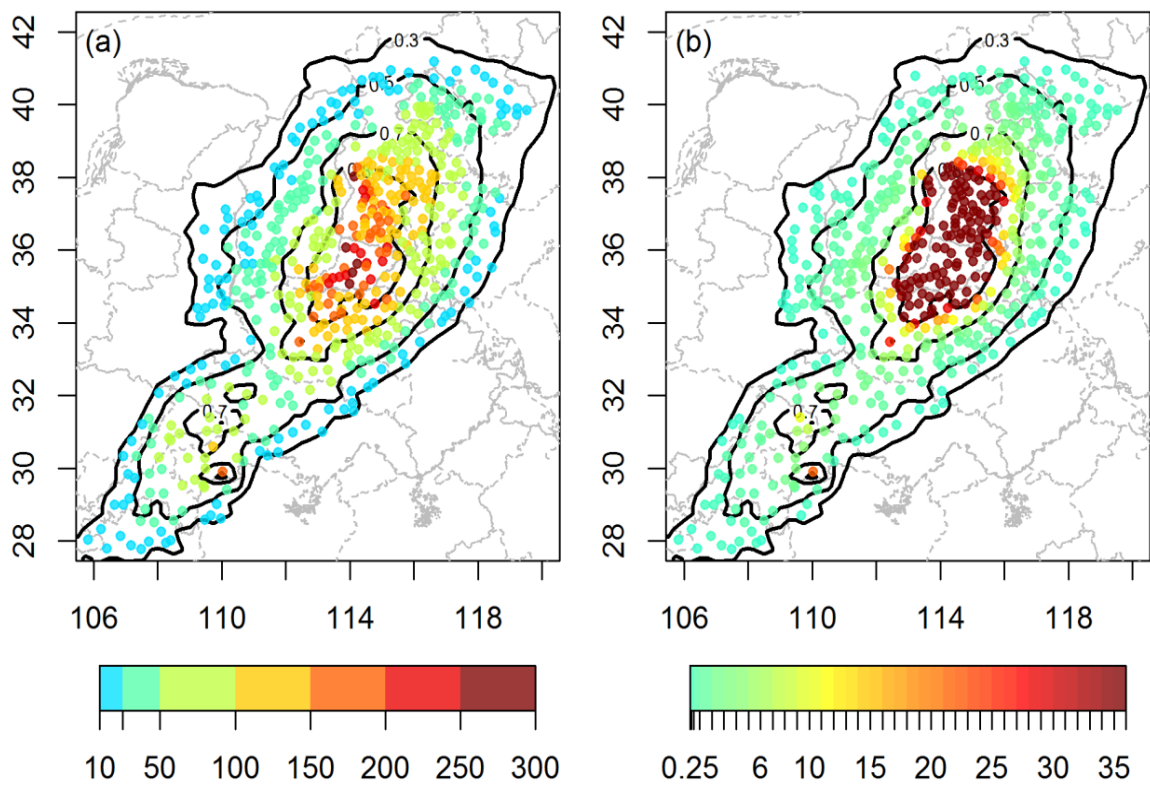

Figure 7. Same as Figure 6(c) and Figure 6(d), but for 84-h forecast. 
precipitation does not happen near the typhoon track. It appears at northeast of Zhejiang province with more than $300 \mathrm{~mm}$ affected by the land-sea and topography (Figure 8(a)). Wet air from the sea is advected by the westward low level jet. When reaching the land, the convection could be triggered by orographic uplift in the conditional unstable air. The convection blocks the water vapor transporting to the center of Meranti. The return periods of the event at East China are about 20 years. The precipitation at south of Jiangsu, southeast of Anhui and north of Zhejiang provinces exceeds the max of climate (Figure 8(b)).

The HRDet model forecast misses the over $200 \mathrm{~mm}$ precipitation event at east of Zhejiang province and overestimates the precipitation along the typhoon track. The EPS performs well with significant probability over $100 \mathrm{~mm}$ at east of Zhejiang province. The EFI based on the EPS performs well too. It is larger than 0.8 at the east of Zhejiang province for 60 and 120 hours lead times forecast (Figure 8). For the 60 -h forecast, the EFIEQ is more than $100 \mathrm{~mm}$ near the landfall area with the observation over $100 \mathrm{~mm}$ too. The HRDet forecasts the precipitation at some area of Fujian province over $100 \mathrm{~mm}$, however the EFIEQ is less than $100 \mathrm{~mm}$ which is closer to the observation. The EFIEQ shows a good indication for the over $100 \mathrm{~mm}$ precipitation at east of Zhejiang province.

The return period of EFIEP shows more bias. It is totally dependent on the EFI. The max of EFI locates at east of Zhejiang and east of Fujian provinces and the return period at these area is the max. The over max precipitation event at south of Jiangsu, southeast of Anhui and north of Zhejiang provinces are underestimated with smaller EFI.

It is indicated that the EFI is nearly the same at east of Zhejiang and west of Fujian province with value over 0.8 for 60 -h forecast. However the EFIEP and return period are different for the two areas. The return periods are over 35 years at east of Zhejiang and about 25 years at west of Fujian province (Figure 8(d)). So it is the effect of $p_{0}$ in the Equation (4). The EFIEP is not dependent on $p_{1}$ only. In the former research [5] [6] [9], the EFI is only correlated to the event's percentile or rank relative to the climate, and the performances for different EFI thresholds for different extreme events are estimated. In this work, the EFI is correlated not only to the percentile but also to the proportion of no precipitation (Figure 2). The $p_{0}$ are about $58 \%$ and $65 \%$ at east of Zhejiang and west of Fujian provinces respectively at 16 September. So for the same EFI, the EFIEP are different for the two areas. It is more realistic to the observation.

The return period forecast of 120 -h forecast is more than 35 years at east of Zhejiang province, indicating extreme precipitation. The EFIEQ shows nearly $300 \mathrm{~mm}$ daily precipitation at those areas, although the exact position of extreme precipitation is biased. For the medium range forecast, the EFI misses the extreme precipitation at south of Jiangsu province and the EFIEP misses too.

\subsection{Heavy Snowfall in Northwest China}

In 19 and 20 February 2017, heavy snow happened at Xinjiang province, China. 

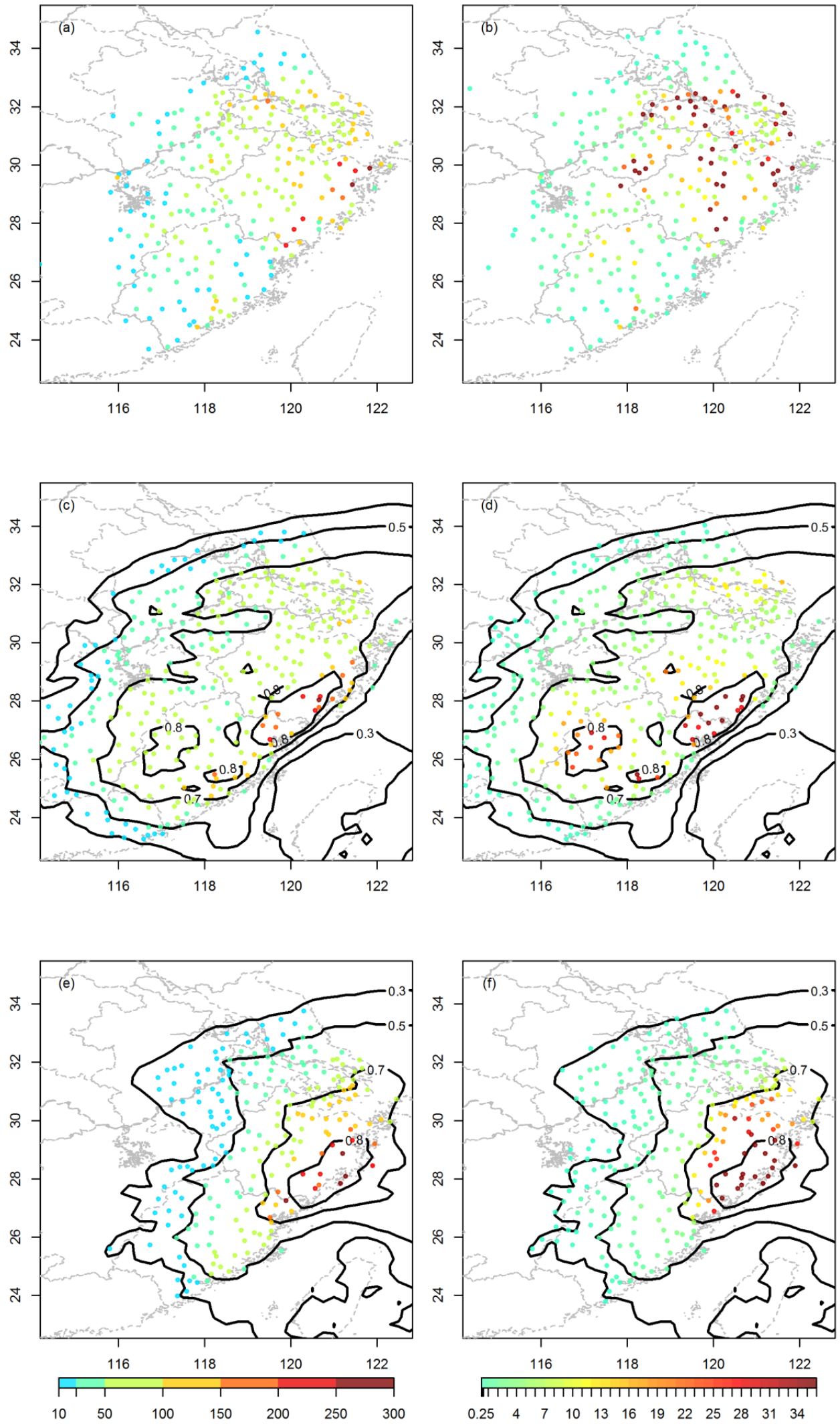

Figure 8. Same as Figure 6, but for the 24 hours precipitation amount from 0000 UTC 15 to 0000 UTC 16 September 2016 and 60-h ((c), (d)) and 120-h forecast ((e), (f)). 
From 0000 UTC 19 to 0000 UTC 20 February, the daily snowfall was about 20 $\mathrm{mm}$ around Urumchi (Figure $9(\mathrm{a})$ ) and it exceeded the max of climate (Figure 9(b)). The heavy snow was affected by a westerly trough which was moving from West Asia about 5 days before. The trough transported water vapor to Xinjiang. As the wet air meet the Tianshan Mountain, topography lifting and the dynamic lifting ahead the trough intensified the snowfall. On the other hand, the Tianshan Mountain whose average altitude is about $5 \mathrm{~km}$ blocked the cold and wet air, and made more precipitation at north of Tianshan Mountain than at the south.

The EFI forecast of 72 hours lead time is about 0.95 around the Tianshan Mountain-including the north and south, indicating extreme precipitation over max of climate. The EFIEQ overestimated the over max precipitation events around the Tianshan Mountain and forecasted more stations over the max of climate. It is demonstrated that although the EFI is similar over the Tianshan Mountain area the EFIEQ was different for north and south of the mountain. So the EFI is not correlated to the precipitation amount directly but to the percentile of the event related to the climate. The EFI show significant difference between north and south of Tianshan Mountain. However the EFIEP all reached the max of climate. The calibration approach is established using all of the stations of China. But the climate characteristics and model biases are different for sub-regions of China. It may be result in the regional bias of this approach and the overestimate at south of Tianshan Mountain.

The EFI forecast of 180 hours lead time show significant difference between north and south of the mountain with larger values at north (Figure 9(e), Figure 9(f)). The EFIEQ indicate the heavy snowfall around Urmchi well. When the EFIEP forecast $100 \%$ percentile-over max of climate, the EFIEQ could not estimate the amount of snowfall over the max which is limited by the climate samples. It is the shortage of EFIEQ.

\subsection{Verification Result}

The EFIEP shows significant skills for percentile forecast. Figure 10 shows the performances of EFIEP for different percentiles of Chinese 2311 stations in 2016. The TS and ETS decrease with the elongated lead times and increasing return periods. The TS is about 0.4 and 0.3 for the 36 -h and 180 -h forecast respectively for 1 year return period event. It is about 0.21 and 0.07 for 20 years return period event. The ETS is all larger than 0 and nearly equal to the TS. The forecast bias is around 1 , except the $48-\mathrm{h}, 60$-h and 72 -h forecast which are nearly 1.5 .

Heavy rainfall which is defined as more than $50 \mathrm{~mm}$ precipitation per day in China always results to flood, urban waterlogging, mountain torrent and other related disasters, especially heavy rainfall for continuous days [1]. QPF is important for disaster prevention. The HRDet QPF underestimates the precipitation commonly and the EPS does not give QPF directly.

The EFIEQ underestimates the precipitation too (Figure 11). It is resulted 

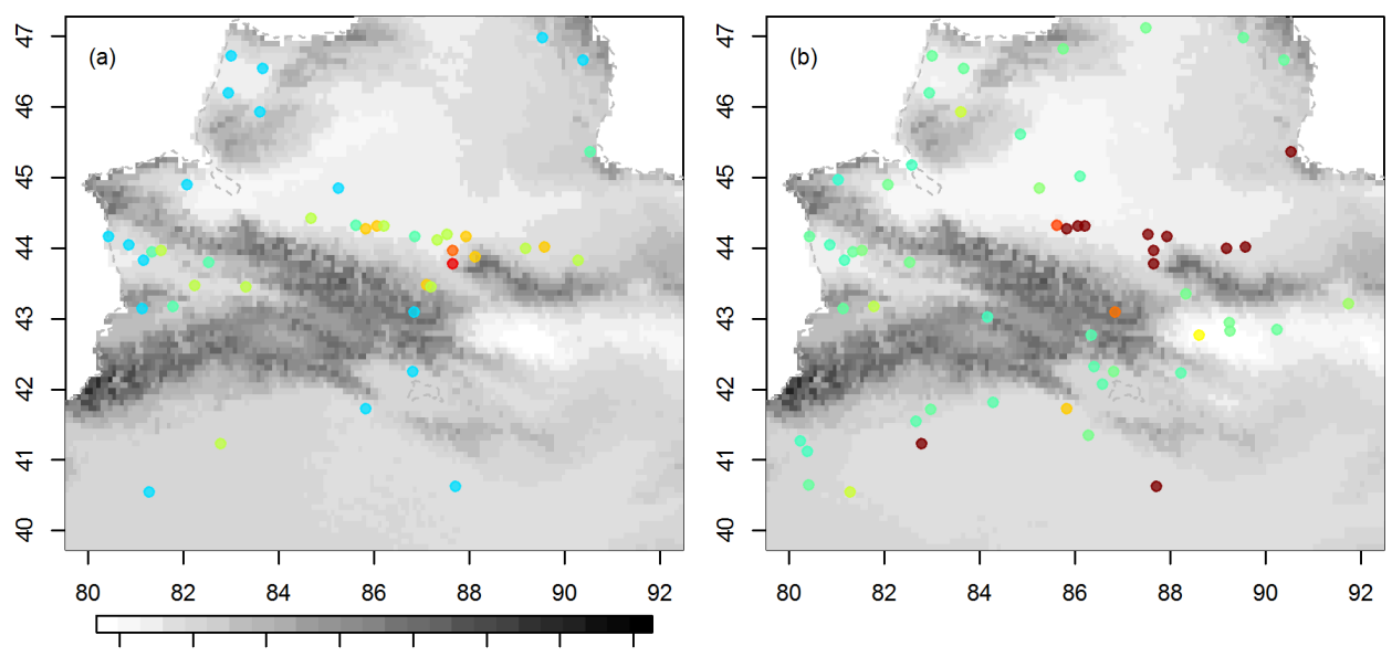

$\begin{array}{llllllll}0 & 1000 \quad 2000 \quad 3000 \quad 4000 \quad 5000 \quad 6000 \quad 7000\end{array}$
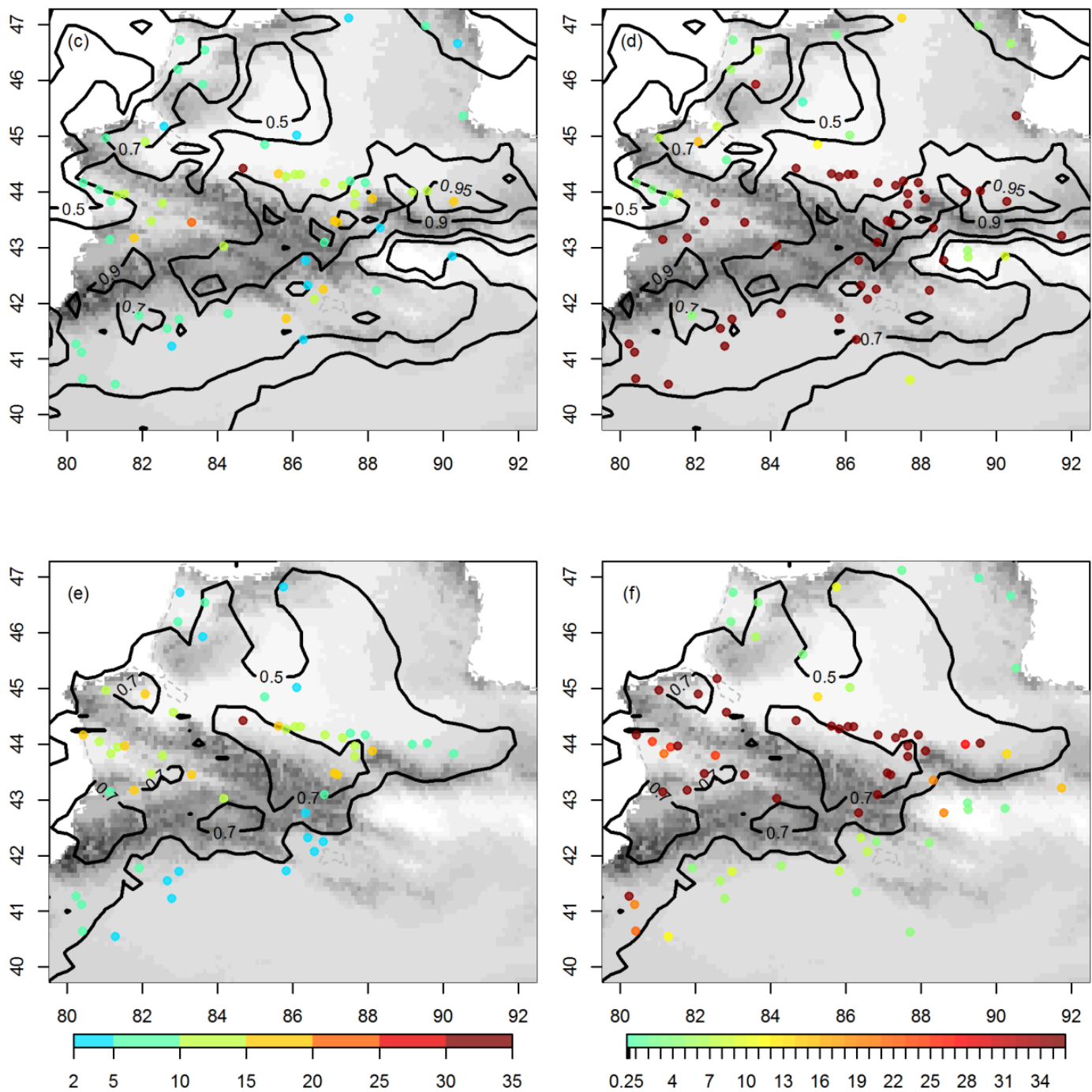

Figure 9. Same as Figure 6 but with the altitude (gray shaded, unit: $\mathrm{m}$ ) and for the 24 hours snowfall amount from 0000 UTC 19 to 0000 UTC 20 February 2017. The lead times are 72 hours ((c), (d)) and 180 hours ((e), (f)). 

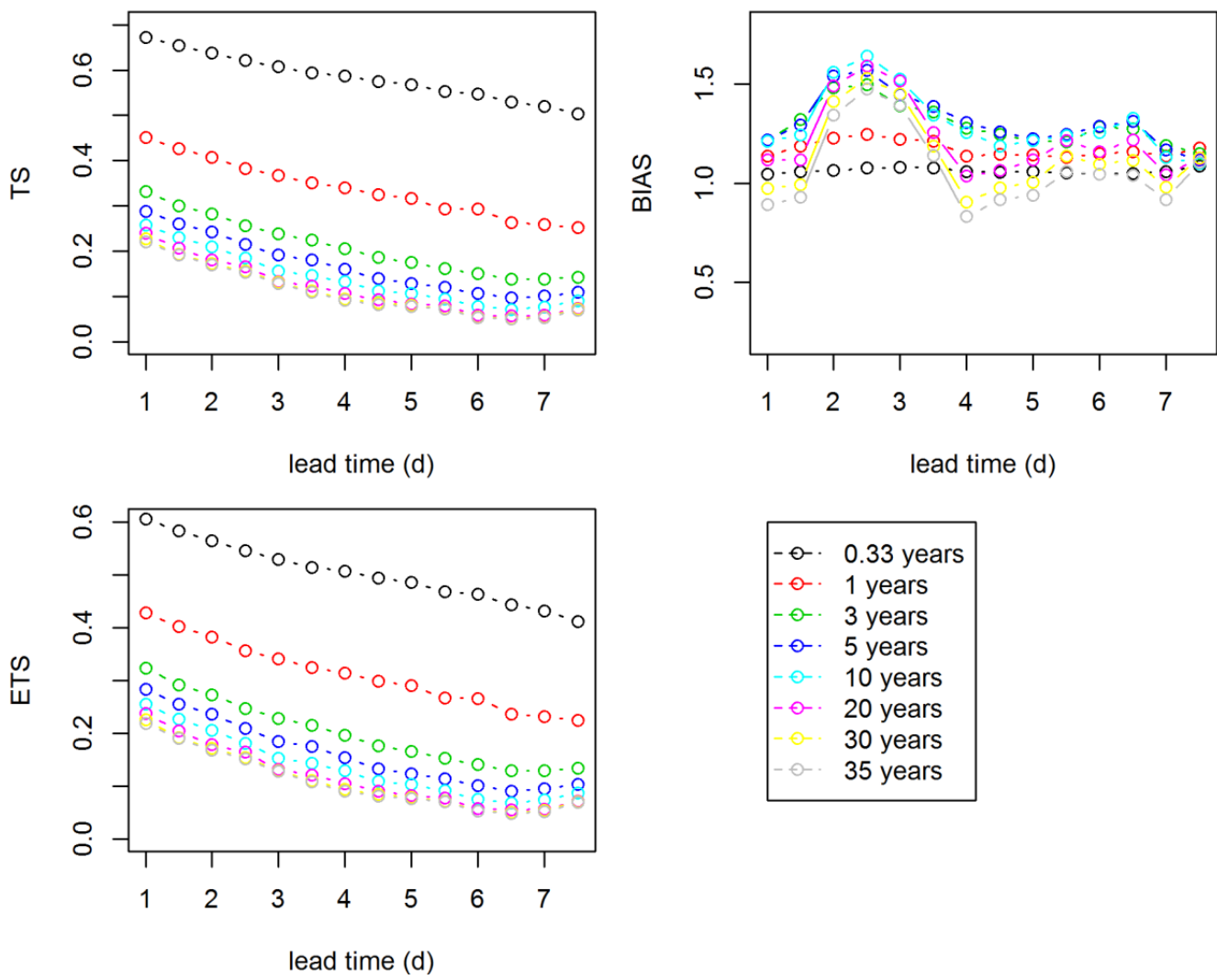

Figure 10. The forecast performances of EFIEP for different percentiles represented by return periods for the 2311 stations of China in 2016.

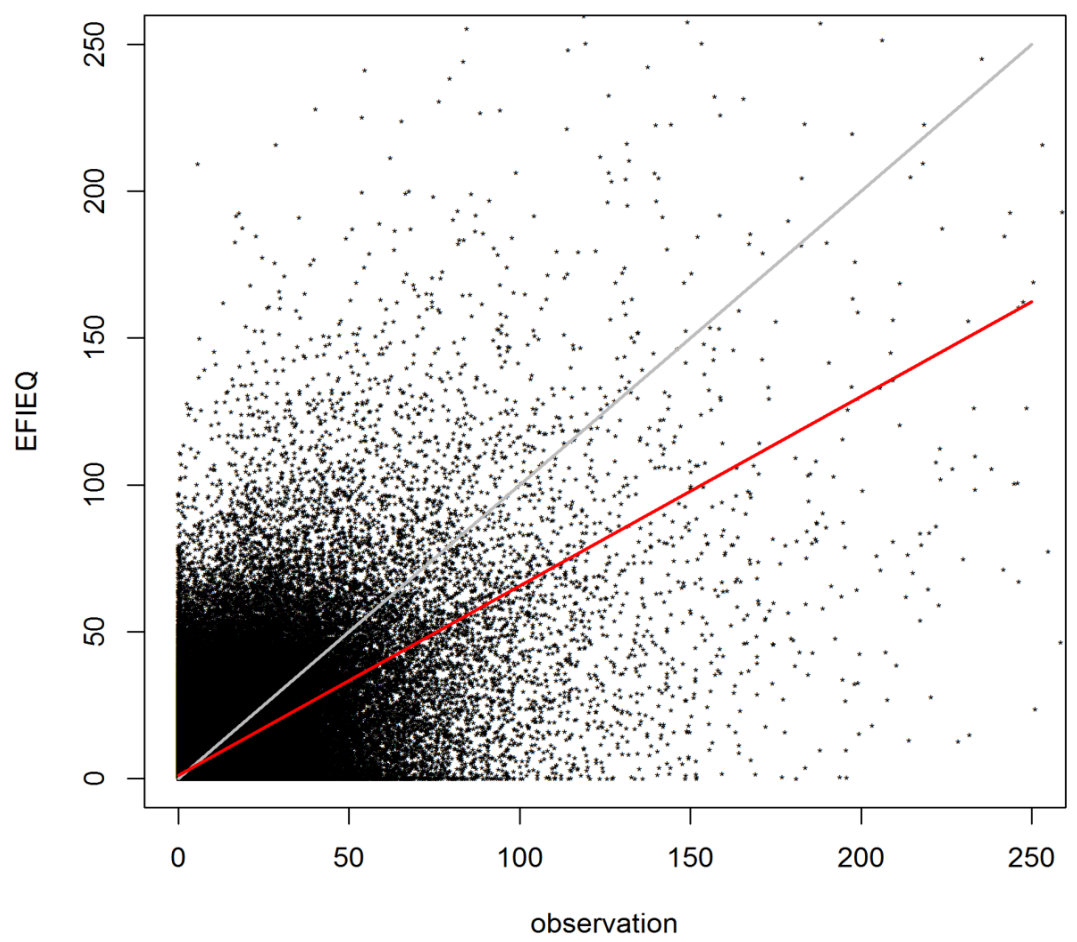

Figure 11. The scatterplot between daily precipitation observations and the corresponding EFIEQ 36-h forecasts for the 2311 stations of China in 2016. The red line indicates the linear fit by least square method. 
from the quantile estimation from the real climate, partly. No matter how extreme the event is, the quantile estimated from the real climate is equal to or less than the max. The less the real climate samples are, the more events with over max would happen. The real climate is established by the last 35 years samples and it is not a long enough periods. The other reason may be the climate of 2016 under the background of super El Niño [29]. The El Niño happened in 2015/ 2016 is the strongest since the observation records started in 1951. Short-time rainstorms occurred much more in 2016 than normal, resulting in the most extreme precipitation events since 2000. The days of extreme rainfalls in North China were the second most since 1981 and the North China rainfall amount in the 18 - 20 July severe precipitation event (Figure 6) exceeded the max of precipitation in the corresponding period in history. If the "weather" had not happened in the "climate", the calibration using the climate data would fail.

The EFIEQ forecast TS of heavy rainfall for 2311 stations of China in 2016 is 0.23 and 0.07 for 36 and 180 hours lead times respectively. The TS of over 100 $\mathrm{mm}$ /day events is 0.15 and 0.03 for 36 and 180 hours lead times respectively. They are larger than that of HRDet (Figure 12(a)). Compared to the significantly less than 1 forecast bias of HRDet, the EFIEQ forecast bias is close to 1 . The bias for lead times 48,60 and 72 hours are about 1.2 for $25 \mathrm{~mm}, 50 \mathrm{~mm}$ and $100 \mathrm{~mm}$ event and the bias of $100 \mathrm{~mm}$ are about 0.6 ahead 4 days lead times (Figure 12(b)).
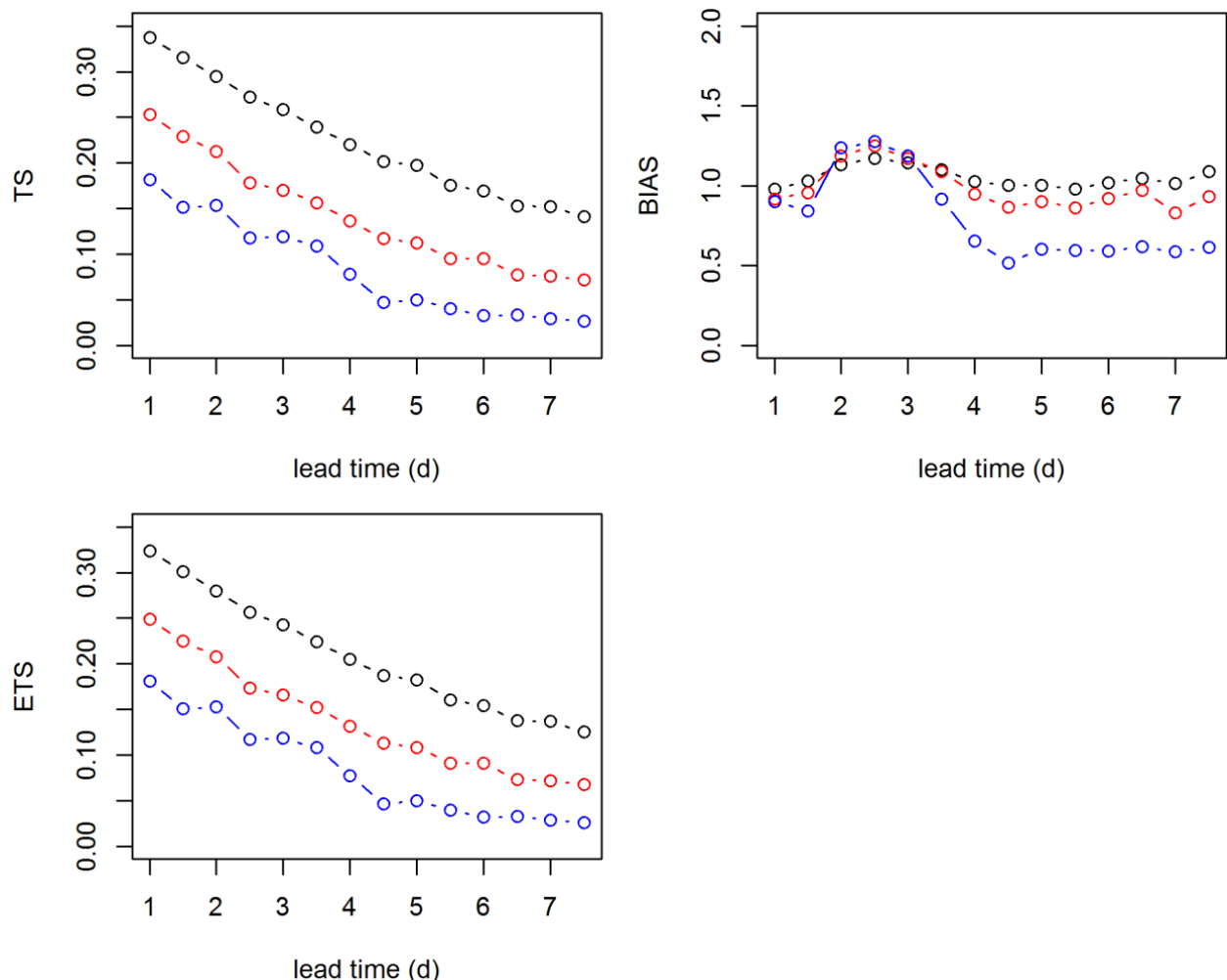

Figure 12. The forecast performances of EFIEQ for different thresholds (black: $25 \mathrm{~mm} /$ day, red: $50 \mathrm{~mm} /$ day, blue: $100 \mathrm{~mm} /$ day). 


\section{Summary and Discussion}

By defining the OEFI of the daily precipitation observation, the EFI is calibrated and can be understood explicitly. EFIEP and EFIEQ are designed based on the EFI to forecast the percentile and quantile of daily precipitation. So the extreme daily precipitation can be forecasted quantitatively. Compared to the past work, this approach shows that the EFI is related not only to the percentile but also to the proportion of no precipitation. As a result, the EFIEP is a function of EFI and proportion of no precipitation.

1) The EFIEQ forecasts the over $200 \mathrm{~mm}$ daily precipitation on 19 July 2016 and some stations exceed the max of climate of corresponding period from 1981 to 2015 , although the extreme daily precipitation about $300 \mathrm{~mm}$ cannot be forecasted by EFIEQ because of the limitation of climate samples. The EFIEP forecasts $100 \%$ percentile at some stations, indicating the daily precipitation over max of climate. The meaning of EFI is not direct, but the EFIEP is explicit.

2) Compared to the HRDet, the EPS forecasts significant probability of 100 $\mathrm{mm}$ /day precipitation at east of Zhejiang province where the daily precipitation is about $200 \mathrm{~mm}$ on 15 June 2016 after the Meranti landing. The EFIEP forecasts $100 \%$ percentile of daily precipitation at this area and the EFIEQ is around 200 $\mathrm{mm}$, although the exact position of over $200 \mathrm{~mm}$ precipitation is not right. The EFI is nearly the same in east of Zhejiang and west of Fujian province, but the EFIEP is different in the two areas. This is resulted from the characteristic of EFIEP which is a function of EFI and proportion of no precipitation. The EFIEP and EFIEQ are valid for the extreme snowfall at north of China. The forecast biases of EFIEP and EFIEQ are close to 1 which is a good performance compared to the HRDet with less than 1 forecast bias. The TSes are about 0.21 and 0.07 for 20 years return period event for 2311 stations of China in 2016. The ETS is all larger than 0 and nearly equal to the TS. The EFIEQ forecasts that TS of heavy rainfall for 2311 stations of China in 2016 is 0.23 and 0.07 for 36 and 180 hours lead times respectively. The scores are better than those of HRDet and show significant forecast skills for quantitative forecast of extreme daily precipitation.

3) The EFI cannot give information about some of the characteristics of the EPS CPDF tail. It is the disadvantage of EFI [16]. So, when an over max of climate event is forecasted by the EPS, the EFI cannot indicate the intensity of the event. The disadvantage of EFI cannot be overcome by the EFIEP and EFIEQ which are based on the EFI and real climate. The EFIEQ is less than or equal to the max of real climate all over which makes the EFIEQ underestimate the daily precipitation commonly. If the event has not been happened in the real climate, it cannot be forecasted by the EFI, EFIEP and EFIEQ.

In order to measure the extremity of EPS CPDF tails, the "Shift of Tails" (SOT) is considered [16]. It is a good addition for EFI. It increases with the extremity of event with no upper limit and performs better than EFI for medium range forecast especially [21]. So next work would use the SOT to modify the 
EFIEQ and give a more considerable QPF of over max extreme event.

The study found that the prediction ability of EPFI for persistent heavy rainfall is obviously higher than that of control forecast, especially for the weaker continuous heavy rainfall forecast. However, there is also a little more than a blank case.

\section{Acknowledgements}

This work was funded by the National Science and Technology Support Program (2015BAC03B01, 2015BAC03B03) of china, the R\&D Special Fund for Public Welfare Industry (Meteorology) (GYHY201306002), and the Meteorological Key Technology integration Program (CMAGJ2015Z06).

\section{References}

[1] Quan, D., Chen, X. and Chen, T.X. (2011) Characteristics and Changes of Extreme Precipitation in the Yellow-Huaihe and Yangtze-Huaihe Rivers Basins. Climate, 24, 3781-3795. https://doi.org/10.1175/2010JCLI3653.1

[2] Legg, T.P. and Mylne, K.R. (2004) Early Warnings of Severe Weather from Ensemble Forecast Information. Weather and Forecasting, 19, 891-906. https://doi.org/10.1175/1520-0434(2004)019<0891:EWOSWF>2.0.CO;2

[3] Lalaurette, F. (2003) Early Detection of Abnormal Weather Conditions Using a Probabilistic Extreme Forecast Index. Quarterly Journal of the Royal Meteorological Society, 129, 3037-3057. https://doi.org/10.1256/qj.02.152

[4] Andersson, E., Anders, P. and Tsonevsky, I. (2015) User Guide to ECMWF Forecast Products. ECMWF, Livelink, 63-67.

[5] Petroliagis, T.I. and Pinson, P. (2012) Early Warnings of Extreme Winds Using the ECMWF Extreme Forecast Index. Meteorological Applications, 10, 1002-1339.

[6] Boisserie, M., Descamps, L. and Arbogast, P. (2016) Calibrated Forecast of Extreme Windstorms Using the Extreme Forecast Index (EFI) and Shift of Tails (SOT). Weather and Forecasting, 31, 1573-1589. https://doi.org/10.1175/WAF-D-15-0027.1

[7] Liu, L., Chen, J., Cheng, L., et al. (2013) Study on Ensemble-Based Forecast of Extremely Heavy Rainfalls in China: Experiments for July 2011 Cases. Acta Mechanica Sinica, 27, 170-185.

[8] Prates, F. and Buizza, R. (2011) PRET, the Probability of RETurn: A New Probabilistic Product Based on Generalized Extreme-Value Theory. Meteorology, 137, 521-537. https://doi.org/10.1002/qj.759

[9] Quan, D., Dai, K., Zhou, J. and Tao, Y.W. (2017) Application and Verification of Extreme Weather Forecast Products of ECMWF Ensemble Prediction System. $\mathrm{Me}$ teorological Monthly, 43, 1095-1109.

[10] Grumm, R.H. and Hart, R. (2001) Standardized Anomalies Applied to Significant Cold Season Weather Events: Preliminary Findings. Weather and Forecasting, 16, 736-754. https://doi.org/10.1175/1520-0434(2001)016<0736:SAATSC $>2.0 . C O ; 2$

[11] Guan, H. and Zhu, Y. (2017) Development of Verification Methodology for Extreme Weather Forecasts. Weather and Forecasting, 32, 479-491. https://doi.org/10.1175/WAF-D-16-0123.1

[12] Hamill, T.M., Hagedorn, R. and Whitaker, J.S. (2008) Probabilistic Forecast Cali- 
bration Using ECMWF and GFS Ensemble Reforecasts. Part II: Precipitation. Monthly Weather Review, 136, 2620-2632. https://doi.org/10.1175/2007MWR2411.1

[13] Hagedorn, R., Hamill, T.M. and Whitaker, J.S. (2008) Probabilistic Forecast Calibration Using ECMWF and GFS Ensemble Reforecasts. Part I: Two-Meter Temperatures. Monthly Weather Review, 136, 2608-2619. https://doi.org/10.1175/2007MWR2410.1

[14] Hamill, T.M. (2012) Verification of TIGGE Multimodel and ECMWF Reforecast-Calibrated Probabilistic Precipitation Forecasts over the Contiguous United States. Monthly Weather Review, 140, 2232-2252. https://doi.org/10.1175/MWR-D-11-00220.1

[15] Zsótér, E. (2006) Recent Developments in Extreme Weather Forecasting. ECMWF Newsletter, 107, 8-17.

[16] Brier, G.W. (1950) Verification of Forecasts Expressed in Terms of Probability. Monthly Weather Review, 78, 1-3. https://doi.org/10.1175/1520-0493(1950)078<0001:VOFEIT>2.0.CO;2

[17] Friederichs, P. and Hense, A. (2007) Statistical Downscaling of Extreme Precipitation Events Using Censored Quantile Regression. Monthly Weather Review, 135, 2365-2378. https://doi.org/10.1175/MWR3403.1

[18] Ebert, E.E. (2001) Ability of a Poor Man's Ensemble to Predict the Probability and Distribution of Precipitation. Monthly Weather Review, 129, 2461-2480. https://doi.org/10.1175/1520-0493(2001)129<2461:AOAPMS>2.0.CO;2

[19] Maraun, D. (2013) Bias Correction, Quantile Mapping, and Downscaling: Revisiting the Inflation Issue. The Journal of Climate, 26, 2137-2143. https://doi.org/10.1175/JCLI-D-12-00821.1

[20] Tsonevsky, I. and Richardson, D. (2012) Application of the New EFI Products to a Case of Early Snowfall in Central Europe. ECMWF Newsletter, 133, 4-5.

[21] Graham, N.E. (1994) Decadal-Scale Climate Variability in the Tropical and North Pacific during the 1970s and 1980s: Observations and Model Results. Climate Dynamics, 10, 135-162. https://doi.org/10.1007/BF00210626

[22] Zhou, T., Zhang, J., et al. (2009) Why the Western Pacific Subtropical High Has Extended Westward since the Late 1970s. Climate, 22, 2199-2215. https://doi.org/10.1175/2008JCLI2527.1

[23] Hu, Z.-Z. (1997) Interdecadal Variability of Summer Climate over East Asia and Its Association with $500 \mathrm{hPa}$ Height and Global Sea Surface Temperature. Journal of Geophysical Research, 102, 19403-19412. https://doi.org/10.1029/97JD01052

[24] Hu, Z.-Z., Yang, S. and Wu, R. (2003) Long-Term Climate Variations in China and Global Warming Signals. Journal of Geophysical Research, 108, 4614.

https://doi.org/10.1029/2003JD003651

[25] Gong, D.Y., and Chang, H.H. (2002) Shift in the Summer Rainfall over the Yangtze River Valley in the Late 1970s. Geophysical Research Letters, 29, 1436. https://doi.org/10.1029/2001GL014523

[26] Fu, J.L., Ma, X.K., Chen, T., et al. (2017) Characteristics and Synoptic Mechanism of the July 2016 Extreme Precipitation Event in North China. Meteorological Monthly, 43, 528-539.

[27] Chen, T., Lin, J., Zhang, F.H. and Zhong, Q. (2017) Uncertainty Analysis on the July 2016 Extreme Precipitation Event in North China Using Convection-Allowing Ensemble Simulation. Meteorological Monthly, 43, 513-527. 
[28] Magnusson, L. and Thomas, H. (2016) Predicting Heavy Rainfall in China. ECMWF Newsletter, 149, No. 149.

[29] Bi, B.G., Zhang, X.L. and Dai, K. (2017) Characteristics of 2016 Severe Convective convection Weather and Extreme Rainfalls under the Background of Super El Niño. Chinese Science Bulletin, 62, 928-937. (In Chinese)

https://doi.org/10.1360/N972016-01136 